\title{
Approaches to Improving Writing Research, Instruction, and Performance
}

\author{
Peggy McCardle, Brett Miller and Vincent Connelly*
}

\section{Introduction}

To understand the writing process, one needs to understand its developmental origins and progression, the malleability of its component skills, and the socio-cultural value and role of the activity itself. The field of writing research is in the early stages of incorporating developmental insights into theorizing and conceptual development. Hayes and Berninger (2014) offer a developmentally sensitive cognitive model of the development of writing processes, which recognizes three major, highly interactive yet parallel "levels": resource (including attention, working memory, long-term memory, and reading skill), process, and control, all constrained by difficulty level. Rose (this volume) also cites a resource model (that of Bernstein, 200o), where resources are more social and interpersonal, highlighting the critical role of the teacher and the teacher-student relationship in the context of knowledge construction, and where levels of difficulty will depend on individual differences and change over time with development, invoking Vygotsky's zone of proximal development (Vygotsky, 1978). Both models emphasize the need to examine writing development as a dynamic activity that changes with both growth and experience.

Viewing reading and writing through a developmental, longitudinal lens will be critical, as both reading and writing develop and require instructional support well beyond the early grades. Relations, i.e., correlations between component skills and related processes, change over time, and this change must be considered when planning and implementing instructional support or interventions. Careful examination of these correlations should lead to experimen-

* The opinions and assertions presented in this article are those of the authors and do not purport to represent those of the Eunice Kennedy Shriver National Institute of Child Health and Human Development, the U.s. National Institutes of Health, or the U.s. Department of Health and Human Services.

(C) KONINKLIJKE BRILL NV, LEIDEN, 2018 | DOI: 10.1163/9789004346369_012

This is an open access chapter distributed under the terms of the prevailing CC-BY-NC License at the time of publication. 
tal and quasi-experimental studies to determine how best to support learners' current needs as they progress in becoming skilled readers and writers, which can take many years of support and sustained effort. We must not forget that one of the key roles that models play in this research field is to continue to go beyond describing the writing processes per se and illustrate how, and why, development in writing skill occurs over time. The modeling of the writing process can become so complex that future models may risk becoming more descriptive than developmental. Some of the classic models of writing development, while lacking some of the complexity of later models, are very useful for driving forward our questions about how writing develops in children from less skilled to more skilled (e.g., Bereiter \& Scardamalia, 1987). We can then begin to more clearly understand when and where things can go wrong in writing development and so help predict and prevent failure.

\section{The Overall Need for Research}

Understanding how children develop knowledge prior to reading and writing is essential to building an understanding of pre-writing behaviors and can facilitate efforts to distinguish atypical behaviors and thus guide early preventive interventions. Early development of writing builds on foundational oral language, literacy experiences, and activities in the home and community. Early writing-related behaviors provide critical information for understanding the writing development of children with and without later difficulties. Children develop an early recognition of text in the environment and gain knowledge and understanding of surface level characteristics of writing in their language system (e.g., directionality, linearity), and acquire an awareness of discourse through early interactions with parents and caregivers (see Tolchinsky \& Jisa, this volume, for a review of early writing development). Before entering primary school, children often are taught to write their names and learn the names and sounds of letters; these skills are strong predictors of later literacy development (for a review, see National Early Literacy Panel, 2008). An area in need of additional research in early development is our understanding of the emergence of early writing skills; this includes especially how lower level and higher level features of writing are integrated developmentally as children's writing products become increasingly complex as they grow and develop, and as they begin to learn about more complex written products and genres. Some research has suggested that struggling writers fail to integrate lower level and higher level processes (e.g., Dockrell, Lindsay \& Connelly, 2009) and that this failure 
to integrate leads to a "stop-start" dysfluent style of writing where processes are not conducted in parallel but serially (Olive, 2014).

Adolescents and young adults who struggle with writing face diverse challenges of a different sort from younger students just learning to read and write: they are generating more complex written products, using more complex syntax and more sophisticated vocabulary, and are often involved in diverse discourse communities (see Gregg \& Nelson and Myhill \& Jones, this volume, for discussions of older struggling writers). Text generated by older struggling writers tends to be shorter, not as well organized, and contains a greater number of spelling, punctuation, and grammatical problems; these writers often use comparatively simpler words and less sophisticated punctuation and grammar and they often have poorer handwriting, which can affect both the reality and perception of the quality of their writing. They tend to focus on local rather than more global aspects of text, at the expense of overall quality, and are less likely to engage and persist with writing due in part to fewer opportunities to write, or avoidance of such opportunities, and less access to effective instructional practices. The body of research on older struggling writers is smaller than that addressing younger writers, is less definitive regarding whether individualized (or standardized by subgroup) intervention approaches are necessary; there are few samples of adults (with and without learning difficulties) and those few samples tend to consist of university or college students. Additionally, research conducted particularly on subsets of struggling writers often involves smaller samples with frequently inconclusive findings, such as is the case with specific language impairment (see Myhill and Jones, this volume).

Assessment is a key issue for writing across all ages. Scoring written text has been a challenge historically for the field, including in classroom settings, where rubrics are generally used (see for review Jonsson \& Svingby, 2007). Some scoring systems have included more holistic approaches that often give a single ordinal score, but these approaches are less useful with short texts, differentiating learners (because of the gross scaling), and are less sensitive to change over time. Conversely, analytic approaches can provide more complex and detailed information about the individual learner, but often involve more complex training and the development of psychometrically sensitive and reliable subscores. If we focus on what to measure, ideas have also evolved over time with an increased focus on quality, productivity, text complexity and organization, and genre.

Dockrell and Connelly (this volume) discuss the potential of curriculum based measurement (СВM) of writing for providing timely information to monitor progress and to inform targeted instruction. Свм can potentially provide information over time to capture developmental changes, relate these to more 
complex aspects of written text, and identify children who struggle in the acquisition of writing. To generate a comprehensive picture of the writing skills of any individual, Dockrell and Connelly argue, we need comprehensive data collection, rather than focusing on production (often number of words written) in isolation. However, СвMs are not without their own challenges: validity of use across populations of interest, difficulties in scoring, and sensitivity to detecting differences in the quality of text. Despite these challenges, it is feasible to develop and implement specific свмs and obtain valid information. For свмs to have a broader impact, research is needed on their utility across age and developmental ranges, to determine when specific measures are most sensitive to performance changes. One key role of СвMs is to guide instructional practice; however, more research is needed to inform their use and interpretation, as well as to guide changes in practice within various instructional contexts. Other research on свм for assessment in other fields, such as reading or math, have shown that classroom educators can often be unconvinced about the validity of свм tools and that this remains a key barrier to use.

\section{Future Research Directions}

While the chapters in this volume offer a variety of views of writing development, instruction, intervention and assessment, all agree that we should view the field with a broad developmental lens, as in the models of Hayes and Berninger (2014) and Bernstein (2000). O'Rourke et al. (this volume) call for research to enhance our understanding of the development of the individual processes or skills within levels (e.g., the resource level, including attention, working memory, long-term memory, and reading skill in Hayes and Berninger's (2014) framework) and in the integration across levels. Especially for individuals with language-learning and attentional difficulties, understanding the role of resource-level activities and how these may play out in complex non-linear or cascading fashions can provide insights for both the foundational understanding of writing and its relation to reading, but also for the design and implementation of intervention.

Assessment too is essential to not only documenting and tracking growth and progress but also can and should inform instruction and intervention. As noted earlier, research is needed on the utility of свмs across age and developmental ranges, to determine when specific measures are most sensitive to performance changes, and such information can guide changes in both instruction and intervention. It could also help convince classroom educators of the utility of свмs in their daily practice. From a research perspective, an enhanced 
focus on assessment can also inform foundational science by further specifying and refining how we define and operationalize core constructs related to writing development. These refinements can lead to improved specification in our theories and precision of measurement of our constructs.

Reading is a key resource constraint on the development of efficient writing (Hayes \& Berninger, 2014) and a critical functional part of the writing process itself, yet the interaction between reading and writing skills has been little studied (e.g., Miller, McCardle, \& Long, 2014; Wengelin \& Arfé, this volume). Relatedly, there has been some work on the relationships between handwriting and composing (e.g., Kent \&Wanzek, 2016; Limpo, Alves \& Connelly, 2017), such that handwriting could be included as a resource for writing, but additional exploration and replication are needed. Spelling is a key component of transcription and a key constraint on writing from the primary grades through to adulthood for poor spellers; it affects both accuracy and fluency (Sumner, Connelly \& Barnett, 2014; Tops, Callens, van Cauwenberghe, Adriaens \& Brysbaert, 2013). Yet, the complex interactions demonstrated in some recent experimental work (e.g., Kandel \& Spinelli, 2010) are still poorly understood. In addition, language skills are a foundational resource that undergirds both reading and writing, and these skills themselves change developmentally as a key part of literacy mastery. What follow are a few targeted research areas that could individually and collectively contribute to a much richer and deeper understanding of writing development, difficulties, and intervention.

The following are areas drawn largely from the context of the chapters in this volume, in which it is clear that additional research is needed, whether to break new ground or more thoroughly explore areas where some research has been initiated or is ongoing. In addition, there are clearly areas where we need to examine current or recommended practices, either to document their effects or to explore the mechanisms that underlie those effects in order to more thoroughly understand how typically developing writers become successful and why and how some children do not. Such knowledge can lead to better screening and early identification of spelling and writing difficulties, curricula and intervention design, and should lead to changes and enhancements in teacher education and professional development in order for teachers to fully understand children's development in these areas and through that knowledge more effectively educate all children — and enable all children to become effective writers. 


\section{The Underpinnings of Reading and Writing Difficulties}

In seeking to examine the underpinnings of reading and writing difficulties, again a developmental approach holds promise. Perhaps the same or overlapping cognitive or language deficits could underlie both reading and writing problems: for example, poor reading impacts writing because of its key role in the writing process (reading written text and revising) and both processes may be related developmentally. However, several authors have noted the implications of the potential separability of disorders of reading and writing (e.g., see Berninger \& Abbott, 2010; Mehta et al., 2005; see also Peterson, McGrath, Willcutt, Keenan, Olson, \& Pennington, under review, Wagner et al., 2011). Viewed through the lens of practice, in education settings, relatively little support is given for the underpinnings of reading and writing processes (e.g., oral language skills and meta-linguistic awareness, including discourse rules) and the supports that do exist are generally not well integrated.

\section{Meta-Linguistics}

Myhill and Jones note that adolescent struggling writers possess less metacognitive knowledge of the writing process and are less successful in utilizing what they know; they need support for comprehension and to increase their skills in managing the writing process. Noting the importance of the role of teacher knowledge, Myhill and Jones imply that limitations in the teacher's own knowledge may negatively impact struggling writers. In fact, a study of sixth grade teachers' speech (Lesaux \& Gamez, 2012) showed that the quality of teacher language (but not the quantity) had a positive effect on the reading development of native-English speaking and language minority students, supporting the notion that indeed teachers' language can affect learning. At minimum, there is a need for better understanding of the role of teachers' knowledge and ability to demonstrate meta-linguistics in mediating students' development of meta-linguistic knowledge; thus it will also be important to examine the development of these skills in teacher preparation programs.

\section{Morphology}

Morphology, a specific area of metalinguistic awareness, has historically been underrepresented or not included in models of reading and spelling (e.g., Coltheart, Rastle, Perry, Langdon, \& Ziegler, 2001; Seidenberg \& McClelland, 1989; although see for example Taft, 1979; for discussion in the context of connectionist models see Rueckl, 2010, and Gonnerman, Seidenberg, \& Andersen, 2007). Enhancing such integrative accounts could advance theoretical understanding of reading development, spelling and reading for those who struggle in these areas, and especially of normative spelling (which is and instructionally 
should be far more than a mechanical rote-memory task; see Silliman, Bahr, Nagy, \& Berninger, this volume). In addition, better integrative explanations could provide important tests and potential constraints on morphology's role in literacy development. Spelling depends upon the interconnections between phonology, orthography, and morphology and the mapping among these factors. Silliman et al. highlight that the relative frequency of legal (within the orthography) letter groupings may affect their accessibility; this is consistent with general learning principles from statistical learning models (e.g., see Harm \& Seidenberg, 1999), which offer an opportunity for deeper exploration.

We need an enhanced understanding of the basic development of morphological knowledge and its interconnectedness with other forms of lexical information. Some recent work in this area shows potential promise with both typical (McCutchen, Stull, Herrera, Lotas \& Evans, 2014) and struggling writers (Critten, Connelly, Dockrell \& Walter, 2015), but much remains to be explored. This is true not only for English, a morphophonemic morphologically rich language, but also for the full range of languages and orthographies. Silliman et al. argue that through the lens of morphology, English becomes more transparent, and a cogent presentation of this is made by Henry \& Calfee (2003) and Moats (2005). But the discussion of possible inter-language differences in the balance or level of transparency at different levels of analysis extends to many languages, informed by linguistic analyses (e.g., Kieffer \& Lesaux, 2012; McBride-Chang et al., 2005; Schiff, Schwartz-Nahshon, \& Nagar 2011; Wang, Ko, \& Choi, 2009). However, the implications for struggling writers and spellers is less clear and likely complex, particularly when we think about the dynamics of the developing writing (cognitive) system for struggling writers, vis-à-vis Hayes and Berninger (2014), and how it varies by writing system. Research on the role of morphology in designing interventions for struggling readers and writers within and across languages, and in teacher education, is an important area for future exploration.

\section{Self-Efficacy and Executive Functions}

While terms like self-efficacy, motivation, executive function or executive control are much discussed, research to focus on the specific behaviors they encompass and their impact on literacy—both reading and writing, is sparse (e.g., see though Berninger, Abbott, Cook, \& Nagy, 2017). Key components of persistence, including self-regulation, self-efficacy, and goal orientation, relate both directly and indirectly to an individual's general cognitive processing abilities and affective response to the task of writing (e.g., see Santangelo, Harris, \& Graham, 2016). Individuals with specific learning disorders (SLDs) have an increased likelihood of difficulties with self-regulation in the context of writ- 
ing, which can interfere with the planning, production, and revision processes. Struggling writers have lower reported self-efficacy for writing and are less likely to think of and/or utilize information about the audience for the written product (Troia, Shankland, \& Wolbers, 2010). Within the research on struggling readers, especially adolescents and adults, there is also a general lack of attention to motivation and its role in writing and to the intersection of writing and executive function.

\section{Digital Literacy}

With the increased need to write in digital environments, there is a need to focus on digital writing strategies for diverse learners so that struggling writers can more effectively produce text appropriate for the "genre" constraints of those environments. Rønneberg, Johansson, Mossige, Torrance, and Uppstad (this volume) present a practical view for how technology could support struggling writers by adopting an alternative, writer-centric perspective. They call for a move from the current largely negative feedback system that writing technologies provide (e.g., indicating misspellings, focus on grammar) to a more optimally timed, focused, positive feedback. Current feedback mechanisms are at best difficult for struggling writers to fully utilize, and at worst detract from production. For example, in the case of spelling feedback, it is generally assumed that the writer can identify the correctly-spelled word if presented, which unfortunately is often not the case for struggling writers (See Sumner, Connelly \& Barnett, In Press). Rønneberg and colleagues (this volume) suggest that delaying this type of feedback could not only allow the struggling writer to focus on writing production/fluency but also provide additional information from the text that would constrain later-presented word candidates for misspelled items. More holistically, technology solutions need to be reoriented away from WYSIWYG (what you see is what you get) to WYGIWYN (what you get is what you need). The key distinction here is to emphasize writing fluency over correction; this approach could enhance text generation for struggling writers by de-emphasizing correction and focusing activity (and attention) on production. Consistent with this argument, individuals with dyslexia can produce text comparable to those without dyslexia when the text is hidden after it is written, i.e., not allowing for revisions.

Rønneberg et al. (this volume) highlight an intelligent writing tool that detects the use of difficult items for a struggling writer based upon previous experience and gives positive feedback, encouraging and motivating the writer. At this point, these concepts are largely not instantiated in current tools and vary in their complexity of implementation-e.g., delaying feedback on possible errors until a later revision phase would be straightforward to implement, 
whereas identifying areas of difficulty and providing positive, timely feedback based upon future use is feasible but more complex.

To fully realize the potential of technological tools to improve writing fluency and quality for struggling writers, the research community will need to creatively combine and flexibly utilize a range of methodological approaches to keep up with the pace of technology development. Given the time required to obtain efficacy data, the delay from conceptualization to funding to research to publication, technology will have already advanced in ways that may make the work less relevant. These challenges are not insurmountable, but necessitate nimble and creative research methodologies to collect timely data that can meaningfully inform practice while maintaining high evidentiary standards. Schools and classrooms are already incorporating technology, largely with little to no data to inform its efficacious use, and will likely continue as new technologies and additional technology vendors enter the education space.

\section{Teacher Education}

Several of the authors in this volume join the plea for improvements in teacher education to prepare these professionals to effectively instruct and intervene in the areas of reading and writing. They decry the paucity of research on struggling writers that teachers can directly utilize, and recent reports show that classroom teachers feel less well prepared when teaching struggling writers (e.g., Dockrell, Marshall \& Wyse, 2016). We have noted specifically the need for greater depth of knowledge in specific areas of linguistics (metalinguistics, and in particular for English, morphology and its importance in spelling, and the impact a teacher's language can have in building student language skills). For example, explicit instruction to facilitate metalinguistic awareness of word forms and their interconnections may be beneficial for those individuals with and without spelling difficulties, and supporting awareness of the connections among phonology, orthography, and morphology and semantics (word meaning) can be an effective tool for enhancing idea expression in struggling writers. While the efficacy of specific interventions to accomplish this should be studied, its implementation and corresponding fidelity can only happen if teachers are knowledgeable about those connections and how best to present them.

In addition, there are other areas of human development about which teachers must have some depth of knowledge - motivation, executive function, cultural differences. While many teachers are aware of these areas and seek additional education about them, courses in child or human development should be a standard part of teacher preparation. 
We call for an increase in research on the impact of digital writing, and this too should be a focus of ongoing teacher preparation and professional development, as the digital world changes rapidly and teachers must somehow keep pace, not an easy task. We ask much of today's (and tomorrow's) teachers - the demands of their job and time will likely only increase. The least we can do is provide the supports necessary such that they, like their learners, can thrive. Literacy training (pre- or post-service) does not occur in a vacuum; teachers need the opportunity to plan, practice, and reify their teaching practices, and administrators and schools need to enhance systemic and systematic supports for system-wide improvements in writing instruction in their schools.

\section{Conclusion}

In conclusion, this volume aimed to provide insights into the state of science and practice for writing development in struggling learners. The paths to becoming a struggling writer are heterogeneous, with individuals possessing primarily language, reading, or writing impairments, (or combinations of these), which may be biologically based, environmentally induced through disadvantage and poor quality instruction, or from other potential etiologies. Models of writing development must become increasingly sensitive and specific, to account for the spectrum of writers that appears in classrooms around the world. This necessitates a better understanding of the developmental trajectories for normative and atypical writing, with an eye toward rich phenotypic data that could more fully inform our understanding of risk in a way that might allow us to proactively address potential problems before they manifest. Normative data also could inform classification and identification approaches to writing disabilities and their potential separability from reading disability or language impairment in a clinical diagnostic context.

This in turn hinges on our ability to successfully measure written products with assessments that are sensitive to developmental differences and changes over time. If we are to see improvements in learners' performance, we must continue to focus on strengthening the power of writing instruction and interventions across the developmental span, on optimizing content and dosage for those at-risk or with demonstrated difficulties, and on more systematically describing the nature of the counterfactual in efficacy studies. At one level, the hope is that effect sizes for our interventions will in fact decrease in the near term due to enhancements in the nature of the writing instruction (and outcomes) in the counterfactual, particularly in a business-as-usual context; in 
other words, one hopes that the quality of writing instruction in public and private education will improve to such an extent that it will be hard to develop substantially better instructional writing programs (and that such programs would no longer need to be developed!). Unfortunately, we are currently far from that as a reality.

Additionally, there is a paucity of long-term outcome studies for writing interventions; we largely do not know the long-term impact of interventions (e.g., 2-4 years after they have ended). Such data will be critical in factoring out changes attributable to development itself and the influence of accumulation of background knowledge, so that we can more clearly examine concepts of instructional dosage, intensity, and grouping moving forward.

In short, the field has made substantive progress, but the road is long and will likely be rough and winding as we move forward to improve outcomes for struggling writers. Significant research attention is needed for these understudied groups if we are to enhance instructional approaches with the goal of substantive, sustained long-term gains in performance. Coherently connecting different lines of research on writing from basic foundational conceptualizations of the writing process through to intervention and measurement, and back to foundational research will be critical to advancing both science and practice. Although difficult, such an integrated research endeavor is within our reach and capabilities!

\section{References}

Bereiter, C. \& Scardamalia, M. (1987) The psychology of written composition. Hillsdale, NJ: Lawrence Erlbaum Associates.

Berninger, V., \& Abbott, D. (2010). Listening comprehension, oral expression, reading comprehension and written expression: Related yet unique language systems in grades 1, 3, 5, and 7. Journal of Educational Psychology, 102, 635-651.

Berninger, V., Abbott, R., Clayton, C., \& Nagy, W. (2017). Relationships of attention and executive functions to oral language, reading, and writing skills and systems in middle childhood and early adolescence. Journal of Learning Disabilities, 50 (4), 434-449. DOI: 10.1177/oo22219415617167

Bernstein, B. (2000). Pedagogy, symbolic control, and identity: Theory, research, critique. Lanham, MD: Rowan \& Littlefield Publishers, Inc.

Coltheart, M., Rastle, K., Perry, C., Langdon, R., \& Ziegler, J. (2001). DRC: A dual route cascaded model of visual word recognition and reading aloud. Psychological Review, 108, 204-256.

Critten, S., Connelly, V. Dockrell, J.E., \& Walter, K. (2014). Inflectional and derivational 
morphological spelling abilities of children with specific language impairment. Frontiers in Psychology: Cognitive Science, 5:948. doi: 10.3389/fpsyg.2014.00948

Dockrell, J.E., Lindsay, G. \& Connelly, V. (2009). The impact of specific language impairment on adolescents written text. Exceptional Children. 75, 427-426.

Dockrell, J.E., Connelly, V., Walter, K., \& Critten, S. (this volume). The role of curriculum based measures in assessing writing products. In B. Miller, P. McCardle, \& V. Connelly (Eds.), Writing development in struggling learners: Understanding the needs of writers across the lifecourse. Leiden, The Netherlands: Brill Publishers.

Dockrell, J.E., Marshall, C.R., \& Wyse, D. (2016). Teachers' reported practices for teaching writing in England. Reading and Writing, 29(3), 409-434.

Gonnerman, L., Seidenberg, M., \& Anderson, E. (2007). Graded semantic and phonological similarity effects in priming: Evidence for a distributed connectionist approach to morphology. Journal of Experimental Psychology: General, 136(2), 323345 .

Gregg, N., \& Nelson, J. (this volume). Empirical studies on the writing abilities of adolescents and adults with learning disabilities. In B. Miller, P. McCardle, \& V. Connelly (Eds.), Writing development in struggling learners: Understanding the needs of writers across the lifecourse. Leiden, The Netherlands: Brill Publishers.

Harm, M., \& Seidenberg, M. Reading acquisition, phonology, and dyslexia: Insights from a connectionist model. Psychological Review, 106, 491-528.

Hayes, J. \& Berninger, V. (2014). Cognitive process in writing: A framework. In B. Arfé, J.E. Dockrell \& V.W. Berninger (Eds.), Writing development in children with hearing loss, dyslexia or oral language problems: Implications for assessment and instruction (pp. 3-15). New York: Oxford University Press.

Henry, M.K., \& Calfee, R. (2003) Unlocking literacy: Effective decoding and spelling instruction, Edition 1. Baltimore, MD: Brookes Publishing.

Jonsson, A., \& Svingby, G. (2007). The use of scoring rubrics: Reliability, validity, and educational consequences. Educational Research Review, 2, 130-144.

Kandel, S., \& Spinelli, E. (2010). Processing complex graphemes in handwriting production. Memory \& Cognition, 38(6), 762-770.

Kent, S.C., \& Wanzek, J. (2016). The relationship between component skills and writing quality and production across developmental levels: A meta-analysis of the last 25 years. Review of Educational Research, 86(2), 570-6o1. doi:10.3102/oo34654315619491

Kieffer, M.J., \& Lesaux, N.K. (2012). Direct and indirect roles of morphological awareness in the English reading comprehension of native English, Spanish, Filipino, and Vietnamese speakers. Language Learning, 62, 1170-1204 doi: 10.1111/j.1467-9922.2012 .00722.X

Lesaux, N.K., \& Gámez, P.B. (2012). Examining classroom talk in the San Diego Unified School District. Senior Urban Research Fellowship Series, Vol. X (Fall 2012). Washington, DC: The Council of Great City Schools. 
Limpo, T., Alves, R.A., \& Connelly, V. (2017). Examining the transcription-writing link: Effects of handwriting fluency and spelling accuracy on writing performance via planning and translating in middle grades. Learning and Individual Differences, 53, 26-36. doi: 10.1016/j.lindif.2016.11.004

McBride-Chang, C., Cho, J.-R., Liu, H., Wagner, R.K., Shu, H., Zhou, A., ... Muse, A. (2005). Changing models across cultures: Associations of phonological awareness and morphological structure awareness with vocabulary and word recognition in second graders from Beijing, Hong Kong, Korea, and the United States. Journal of Experimental Child Psychology, 92, 140-16o. doi:10.1016/j.jecp. 2005.03.009

McCutchen, D., Stull, S., Herrera, B.L., Lotas, S., \& Evans, S. (2014). Putting words to work: Effects of morphological instruction on children's writing. Journal of Learning Disabilities, 47(1), 86-97. doi:10.1177/oo22219413509969

Mehta, P.D., Foorman, B.R., Branum-Martin, L., \& Taylor, W.P. (2005). Literacy as a unidimensional multilevel construct: Validation, sources of influence, and implications in a longitudinal study in grades 1 to 4. Scientific Studies of Reading, 9(2), $85^{-116 .}$

Miller, B., McCardle, P., \& Long, R. (Eds.) (2014). Teaching reading and writing:Improving instruction and student achievement. Baltimore, MD: Paul Brookes Publishing.

Moats, L. (2005). How spelling supports reading: And why it is more regular and predictable than you may think. American Educator, 12, 42-43.

Myhill, D., \& Jones, S. (this volume). Lost for words: Instructional approaches to support older struggling writers. In B. Miller, P. McCardle, \& V. Connelly (Eds.), Writing development in struggling learners: Understanding the needs of writers across the lifecourse. Leiden, The Netherlands: Brill Publishers.

National Early Literacy Panel (2008). Developing early literacy: Report of the National Early Literacy Panel. Washington, DC: National Institute for Literacy. http://lincs.ed .gov/publications/pdf/NELPReporto9.pdf

Olive, T. (2014). Toward a parallel and cascading model of the writing system: A review of research on writing processes coordination. Journal of Writing Research, 6(2), 173194.

O'Rourke, L., Connelly, V., \& Barnett, A. (this volume). Understanding writing difficulties through a model of the cognitive processes involved in writing. In B. Miller, P. McCardle, \& V. Connelly (Eds.), Writing development in struggling learners: Understanding the needs of writers across the lifecourse. Leiden, The Netherlands: Brill Publishers.

Peterson, R., McGrath, L., Willcutt, E., Keenan, J., Olson, R., \& Pennington, B. (under review). Is the "g" of academic skills the same as the "g" of intelligence?

Rønneberg. V., Johansson, C., Mossige, M., Torrance, M., \& Uppstad, P. (this volume). Why bother with writers? Towards "Good enough" technologies for supporting dyslexics. In B. Miller, P. McCardle, \& V. Connelly (Eds.), Writing development in 
struggling learners: Understanding the needs of writers across the lifecourse. Leiden, The Netherlands: Brill Publishers.

Rose, D. (this volume). Evaluating the task of language learning. In B. Miller, P. McCardle, \& V. Connelly (Eds.), Writing development in struggling learners: Understanding the needs of writers across the lifecourse. Leiden, The Netherlands: Brill Publishers.

Rueckl, J. (2010). Connectionism and the role of morphology in visual word recognition. Mental Lexicon, 5, 371-40o.

Santangelo, T., Harris, K., Graham, S. (2016). Self-regulation and writing. In C. MacArthur, S. Graham, \& J. Fitzgerald (Eds.), Handbook of writing research, 2nd Edition (pp. 174-193.). New York: The Guilford Press.

Schiff, R., Schwartz-Nahshon, S.S., \& Nagar, R. (2011). Effect of phonological and morphological awareness on reading comprehension in Hebrew-speaking adolescents with reading disabilities. Annals of Dyslexia, 61, 44-63. doi: 10.1007/s11881-010-00465

Silliman, E., Bahr, R., Nagy, W., \& Berninger, V. (this volume). Language bases of spelling in writing during early and middle childhood: Grounding applications to struggling writers in typical writing development. In B. Miller, P. McCardle, \& V. Connelly (Eds.), Writing development in struggling learners: Understanding the needs of writers across the lifecourse. Leiden, The Netherlands: Brill Publishers.

Sumner, E., Connelly, V., \& Barnett, A. (2014). The influence of spelling ability on handwriting production: Children with and without dyslexia. Journal of Experimental Psychology: Learning Memory and Cognition, 4o(5), 1441-1447.

Sumner, E. Connelly, V., \& Barnett, A. (In Press). Writing and revision strategies of students with and without dyslexia. Journal of Learning Disabilities.

Taft, M. (1979). Lexical access via an orthographic code: The Basic Orthographic Syllable Structure (Bоss). Journal of Verbal Learning and Verbal Behavior, 14, 638-647.

Tolchinsky, L., \& Jisa, H. (this volume). The multifaceted development of writing. In B. Miller, P. McCardle, \& V. Connelly (Eds.), Writing development in struggling learners: Understanding the needs of writers across the lifecourse. Leiden, The Netherlands: Brill Publishers.

Tops, W., Callens, M., van Cauwenberghe, E., Adriaens, J., \& Brysbaert, M.(2013). Beyond spelling: The writing skills of students with dyslexia in higher education. Reading and Writing, 26, 705-720.

Troia, G.A., Shankland, R.K., \& Wolbers, K.A. (2010). Reluctant writers and their teachers: Changing self-efficacy beliefs through lesson study. In G.A. Troia, R.K. Shanland, \& A. Heintz (Eds.), Putting writing research into practice: Applications for teacher professional development. New York, NY: Guilford Publications.

Vygotsky, L. (1978). Mind in society: The development of higher psychological processes. Cambridge, MA: Harvard University Press.

Wagner, R., Puranik, C., Foorman, B., Foster, E., Wilson, L., Tschinkel, E., \& Kantor, P. 
(2011). Modeling the development of written language. Reading and Writing, 24(2), 203-22O.

Wang, M., Ko, I.Y., \& Choi, J. (2009). The importance of morphological awareness in Korean-English biliteracy acquisition. Contemporary Educational Psychology, 34, 132-142.

Wengelin, Å., \& Arfé, B. (this volume). Reading and writing: Relationship of complementary skills in children with and without writing difficulties. In B. Miller, P. McCardle, \& V. Connelly (Eds.), Writing development in struggling learners: Understanding the needs of writers across the lifecourse. Leiden, The Netherlands: Brill Publishers. 